\title{
Review
}

\section{Sepsis and mechanisms of inflammatory response: is exercise a good model?}

\author{
R J Shephard
}

\begin{abstract}
Objectives-The immune changes induced by a bout of prolonged and vigorous exercise have been suggested to be a useful experimental model of sepsis and the inflammatory response. Available literature was reviewed to evaluate this hypothesis.

Methods-Literature describing the immune response to various patterns of exercise was compared with data on the immune changes observed during sepsis and inflammation.

Results-Although there are qualitative similarities between the immune responses to exercise and sepsis, the magnitude of the changes induced by most forms of exercise remains much smaller than in a typical inflammatory response. Indeed, the exercise induced changes in some key elements such as plasma cytokine concentrations are too small to be detected reliably by current technology. Conclusions-If exercise is to provide a valid model of sepsis and the inflammatory response, it will be necessary to focus on subjects who are willing to exercise extremely hard, to use the pattern of exercise that has the greatest effect on the immune system, and to combine this stimulus with other psychological, environmental, or nutritional stressors. (Br 7 Sports Med 2001;35:223-230)
\end{abstract}

Keywords: sepsis; inflammatory response; exercise; cytokines; endorphins; immune function

Faculty of Physical Education and Health and Department of Public Health

Sciences, University of Toronto and Defence and Civil Institute of Environmental Medicine, Toronto, Ontario, Canada R J Shephard

Correspondence to: Professor Shephard, PO Box 521, Brackendale, BC

VON $1 \mathrm{HO}$, Canada

royjshep@mountain-inter.net

Accepted 3 May 2001
Sepsis constitutes a major cause of morbidity and mortality in patients with severe trauma, burns, or blood loss. Uncontrolled sepsis probably plays a central role in the development of multiple organ failure. ${ }^{12}$ Improvements in resuscitation, anaesthesia, and critical care medicine have made important contributions to prognosis after major surgery and trauma, but, despite these advances, the risks of morbidity and mortality from sepsis remain a significant concern. The major problem in implementing successful treatment is the difficulty in controlling or reversing an excessive systemic inflammatory response. This is triggered by the leakage into the circulation of
Gram negative microorganisms and endotoxins. ${ }^{3-6}$ These processes in turn stimulate the release of a complex cascade of cytokines and mediators.

Progress in developing treatment to minimise the inflammatory complications of severe trauma has been hampered by the lack of appropriate human experimental models.

Conclusions drawn from animal experimentation have been suspect because of interspecies differences in gross and cellular physiology of the immune system, and differences in the time course of inflammatory reactions from those encountered in human subjects. The one human model examined to date was based on the injection of small amounts of endotoxin. ${ }^{7}$ However, during tissue injury, the endotoxin may act in concert with other mediators, and the doses of endotoxin that can be used experimentally represent only a small fraction of those encountered in the complications of trauma. Perhaps for these reasons the reactions to endotoxin stimulus have differed in some respects from those encountered in sepsis. In particular, plasma concentrations of important mediators such as complement, interferon- $\gamma$, interleukin-1 and nitric oxide remain below the threshold of measurement after administration of endotoxin.

Recent research has suggested that prolonged and strenuous physical activity can in itself cause substantial tissue injury, with the potential for an excessive inflammatory reaction, immunosuppression, and such clinical consequences as slow healing or recovery from injury and an increased risk of illness and/or infection. ${ }^{8}$ Detailed studies in our own laboratories $^{8-10}$ and elsewhere ${ }^{11-13}$ have indicated some striking parallels between the complex regulatory and counter-regulatory responses to surgical trauma and the reactions to either a single bout of exhausting exercise, or a prolonged and systematic period of heavy training. As in clinical sepsis, the changes in immune response induced by a prolonged bout of intensive exercise may be of sufficient magnitude to provide an "open window" that allows infection by a number of opportunistic micro-organisms. ${ }^{14} 15$

\section{Parallels with clinical sepsis}

Examples are drawn from research conducted in my own laboratory and papers identified in a 
Table 1 Parallels between immune responses to surgical trauma and stressful bouts of physical activity

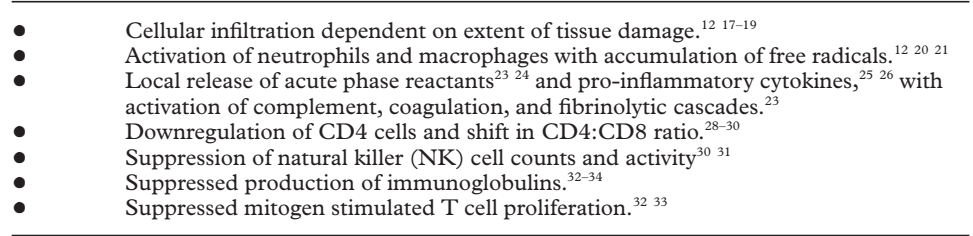

recent symposium on this theme, ${ }^{16}$ together with material from the Compendia of Exercise Immunology Literature of the International Society of Exercise and Immunology, and my own extensive personal files.

Specific changes that have been observed after both surgical trauma and an acute bout of stressful physical activity (table 1) include the following.

(a) Cellular infiltration of the injured or active tissue, ${ }^{11}$ beginning within a few minutes of injury or exercise, and continuing over the next five days. Neutrophils are followed by macrophages, the extent of infiltration in the exerciser being correlated with the extent of subclinical damage to the muscle. ${ }^{17-19}$

(b) Activation of both neutrophils and macrophages, as shown by increased plasma levels of myeloperoxidase, elastase, and neopterin. ${ }^{1120} 21$ There is an associated accumulation of free radicals within the phagosomes and extracellular fluid of the injured muscle, which can be monitored by chemiluminescent techniques. ${ }^{22}$ (c) A local release of acute phase reactants, particularly eicosanoids ${ }^{23}$ and the secretion of proinflammatory cytokines interleukin (IL)-1, IL-6, and tumour necrosis factor (TNF) $-\alpha .^{25} 26$ These changes lead to the activation of complement, coagulation, and fibrinolytic cascades, ${ }^{23}$ with systemic overflow and tissue damage apparently related to the extent of IL-1 and IL-6 release and their persistence in the injured tissue. ${ }^{27}$

(d) Modulation of the in vitro production of cytokines by peripheral blood mononuclear cells (e.g. a late decrease in the production of IL-1, IL-2, TNF- $\alpha$, and interferon (IFN)- $\gamma$ by mitogen stimulated peripheral blood mononuclear cells ${ }^{28}{ }^{29}$ ), which is due in part to downregulation of the cytokine secreting $\mathrm{CD} 4$ cells by the release of prostaglandin $(\mathrm{PG}) \mathrm{E}_{2}$ and in part to a shift in the CD4:CD8 ratio. ${ }^{30}$

(e) Reductions in circulating natural killer (NK) cell counts and NK cell activity, sometimes of relatively short duration, ${ }^{31}$ but occasionally persisting for up to seven days after severe exercise..$^{30}$

(f) Suppressed in vitro production of immunoglobulins, ${ }^{32} 33$ with reduced immunoglobulin concentrations in serum, saliva, and nasal washings. ${ }^{34}$

(g) Decreased proliferation of $\mathrm{T}$ cells in response to mitogens. ${ }^{32} 33$

The sequential release of cytokines seems to be similar in sepsis and after exercise. ${ }^{26}$ The main difference between sepsis and exercise is of degree rather than type. Even when there is a substantial secretion of IL-6, there are only modest increases in concentrations of $\mathrm{C}$ reactive protein, ${ }^{35}$ and other features of a fully developed septic reaction, such as myocardial depression, leucocyte aggregation, and dysfunction of vital organs, are not seen with exercise unless there are other simultaneous stressors (such as severe heat exposure).

\section{Optimisation of model of inflammatory response}

Given that reactions to exercise are generally much less pronounced than during sepsis, any experimental studies of the inflammatory response would need to be based on patterns of exercise that maximised the changes in immune function caused by physical activity. Possible approaches may include: (a) adopting the type of exercise regimen that has been shown to have the greatest effect on health outcomes; $(b)$ meta-analysis of changes in circulating cell counts to determine the pattern of exercise giving the largest disturbance of normal values; (c) experimental comparisons of the response to different volumes of endurance training; (d) experimental comparisons of the response to different types of acute exhausting exercise. Recourse may also be made to special samples such as ultra-endurance competitors, sedentary people who embark aggressively on eccentrically biased exercise, and specialist military forces who are exposed to combinations of arduous exercise, sleep deprivation, and exposure to thermal stress.

\section{MAXIMISING RELATION TO HEALTH}

Several reviews have examined the interactions between intensity, frequency, duration, and volume of physical activity and a person's overall health experience, including both susceptibility to infections ${ }^{1436-38}$ and the risk of cancer. ${ }^{39-41}$

Whether looking at susceptibility to infection or to cancer, large samples must be studied to yield statistically significant results, and in consequence the measures of physical activity adopted by investigators have been rather crude. The development of neoplasms has been ascertained with reasonable certainty, often by post mortem analysis, but the diagnosis of respiratory infection has commonly rested on the responses to simple questionnaires rather than clear proof of infection. ${ }^{15}$

The general conclusion from such research has been that prolonged and vigorous exercise is needed to suppress immune function. ${ }^{38}$ For example, the incidence of infection was increased by running a marathon course, but not by running over shorter distances, and the increase in risk was greatest in those who ran at the greatest speeds. ${ }^{43}$

META-ANALYSIS: EXERCISE PATTERN AND NK CELL COUNTS

In terms of upper respiratory infections, the NK cells are probably the most critical leucocyte subset to consider. The NK cells provide a first broad spectrum defence against viruses and certain types of tumour cells, controlling the early phases of viral replication and killing virally infected cells before the body has produced specific antibodies to the invading microorganism. There is a major biphasic 


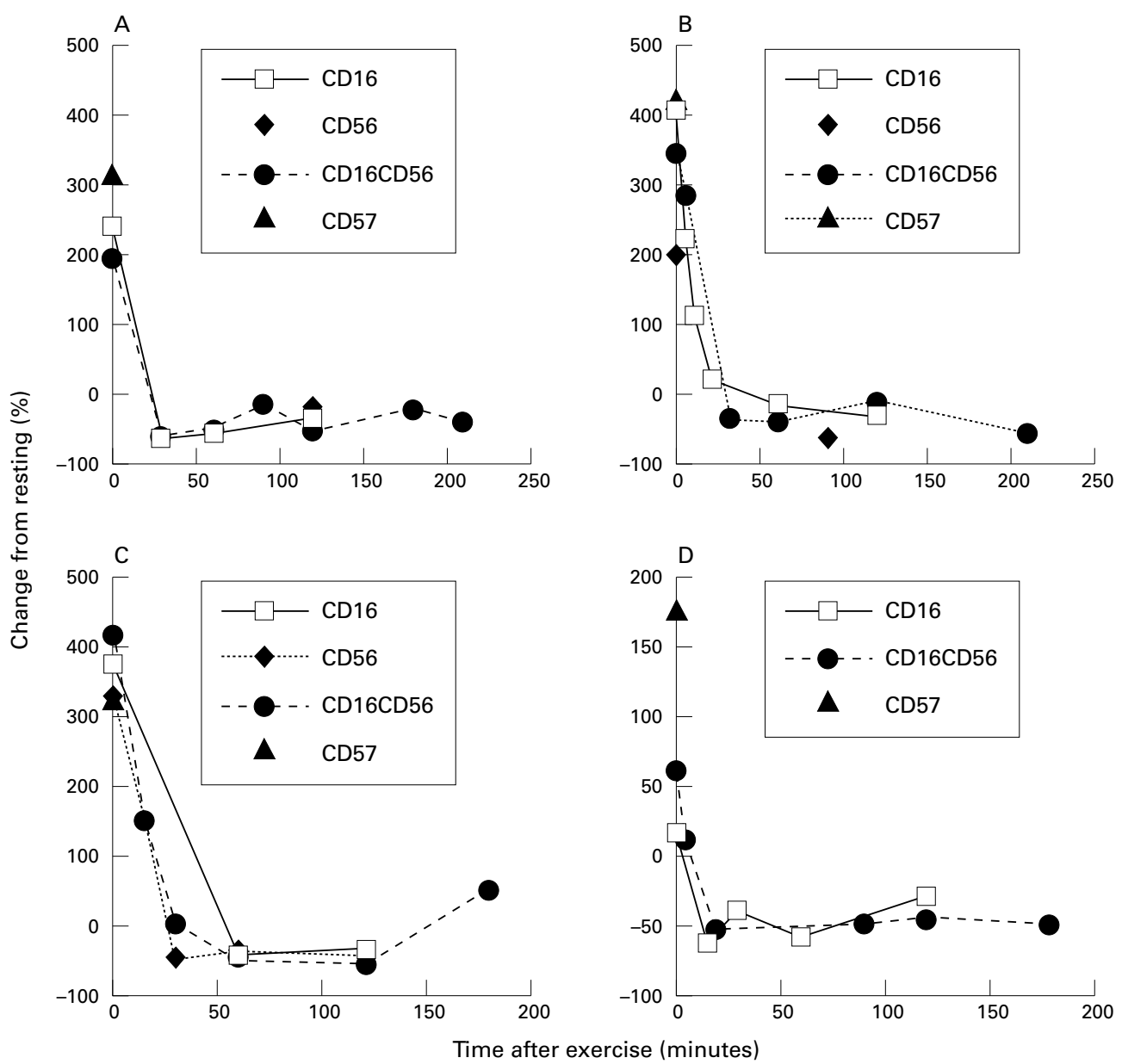

Figure 1 Influence of duration and intensity of effort on natural killer cell count. (A) Sustained moderate exercise; (B) sustained vigorous exercise; (C) brief maximal/supramaximal effort; (D) very prolonged exercise. Taken, with permission of the publishers, from Shephard and Shek. ${ }^{45}$

change in NK cell numbers during and after a bout of vigorous exercise. ${ }^{44}$ The impact of various patterns of physical activity on NK cell counts and function has thus been the subject of a formal meta-analysis. ${ }^{45}$

Data from 94 studies described the NK cell response of some 900 subjects to acute and chronic exercise. Acute exercise was categorised as sustained moderate $(50-65 \%$ of aerobic power), sustained vigorous ( $>75 \%$ of aerobic power), brief maximal or "supramaximal", prolonged, eccentric or resistance, or repeated exercise. In general, there was a pronounced increase in NK cell count at the end of exercise, probably attributable to a catecholamine mediated demargination of cells; further, if exercise was repeated within a short interval, the response tended to be cumulative. $^{3146}$ After exercise, cell counts fell to less than half of normal for a couple of hours, but, unless the activity was prolonged (more than two hours) and vigorous, normal resting values were restored within 24 hours (fig 1). If vigorous activity was exceptionally prolonged (more than six hours), the decrease in NK cell counts and cytolytic activity began during the exercise session. The typical depression of NK cell count seen in a single exercise session seems to be too brief to be of great practical importance for health, but if such changes were to be induced several times a week, as in systematic training, there could be a cumulative adverse effect on immunosurveillance and susceptibility to viral infections.

SIGNIFICANCE OF VENTILATORY THRESHOLD Further evidence on the critical intensity of exercise for development of an inflammatory response was obtained in studies conducted above and below the ventilatory threshold. ${ }^{47} 48$

Responses to 30 minutes of exercise at $80 \%$ and $120 \%$ of ventilatory threshold were compared in healthy young men. ${ }^{47}$ At $120 \%$ of threshold, NK cell counts increased during exercise, but fell below resting values 15, 30, and 60 minutes after exercise; such changes are probably related at least in part to changes in catecholamine concentration. ${ }^{31-49}$ Activity per NK cell was also depressed 30 minutes after exercise, but cytolytic activity per cell remained unchanged. At $80 \%$ of the ventilatory threshold, counts increased during exercise, but did not fall significantly below rest after exercise.

A similar experiment, with exercise bouts limited to five minutes, ${ }^{48}$ showed a significant suppression of NK cell activity 30 minutes after the $120 \%$ effort. Thus, even a brief bout of high intensity effort seems to be sufficient to depress NK cell activity. In this study, $\mathrm{PGE}_{2}$ did not change either during or after exercise, but there 
were decreases in serum cortisol 15, 30, and 60 minutes after exercise, suggesting that not all of the change in cytolytic activity is linked to the inflammatory process.

EFFECT OF TRAINING VOLUME

Studies by Mackinnon ${ }^{34}$ have shown that vigorous exercise can have a cumulative adverse effect on various facets of the immune response; in particular, a depression in immunoglobulin production is coincident with periods of intensive training. A simple cross sectional comparison of the impact of training five rather than three times a week suggested further that, whereas the enhancement of aerobic power was greater with the five days/week stimulus, if the resultant increase in cumulative energy expenditure was sufficient to induce a negative energy balance, there was a modest suppression of immune function, with a decrease in resting B cell (CD19 counts). ${ }^{50}$

PROSPECTIVE STUDY OF THE EFFECTS OF VARIOUS TYPES OF EXERCISE

A recent study compared the immune response to brief, near maximal effort, with sustained aerobic exercise, and a circuit of resistance exercise $^{51}$ (VM Natale, IKM Brenner, P Vasiliou, A Moldoveanu, PN Shek, RJ Shephard, unpublished), all performed at the greatest intensity tolerated by healthy laboratory volunteers. On the basis of earlier observations, ${ }^{26}$ it was hypothesised that subclinical muscle injury would be greatest with the resistance circuit (which required a substantial component of eccentric effort). In fact, all out effort (five minutes at $90 \%$ of maximal aerobic power) yielded similar cellular responses to prolonged exercise (two hours at $60 \%$ of aerobic power), and both were greater than with the circuit training exercise. All three types of exercise induced a significant immediate rise in circulating NK cell counts, but somewhat contrary to expectations, changes were greatest for all out exercise, slightly less for prolonged exercise, and weakest with circuit training. The responses to all three forms of exercise were also much less sustained than in a typical inflammatory response, baseline values being regained three hours after exercise. Total cytolytic activity increased significantly during all out and prolonged exercise, with a parallel but non-significant trend in response to circuit training. In terms of proinflammatory cytokines, plasma IL-6 tended to rise after all out exercise (twofold rise in mean values) and circuit training (1.5 times resting values); however, changes were largest three hours after the prolonged exercise, peaking at a sixfold increase over resting values. $\mathrm{TNF}-\alpha$ showed a small increase with prolonged exercise only, peaking at less than twofold 72 hours after exercise. Changes for both cytokines followed the temporal pattern associated with sepsis, ${ }^{26}$ but were almost two orders smaller than those observed after the challenge of normal subjects with lipopolysaccharides. ${ }^{52}$ The antiinflammatory cytokine IL-10 was significantly reduced by all out exercise, but was unchanged with the other two forms of activity. Muscle soreness was seen in the chest, arms, or legs 24-48 hours after circuit training, and in the legs after prolonged endurance exercise. Serum creatine kinase levels tended to rise 24 hours after circuit training and prolonged exercise. Signs of muscle injury thus showed a different ranking from the leucocyte and cytokine data (circuit training $>$ prolonged $>$ all out exercise), corresponding more closely to our initial hypothesis and studies conducted elsewhere. ${ }^{26}$

This paradox seems an important point of distinction between the exercise model and clinical sepsis. Although the likelihood of microtrauma is greatest with an eccentric form of exercise, prolonged endurance exercise seems to yield the changes in cytokines, leucocytes, and other markers that are most typical of an inflammatory response (below). Further, although all three types of exercise approached the tolerance limit of our sedentary subjects, none were of sufficient severity to induce a substantial and persistent response that could serve as a useful experimental model of sepsis. Possibly, a sample of athletes may be willing to exercise to the point of causing more substantial muscle microtrauma, and thus provide a more serviceable model.

\section{CHARACTERISTICS OF AN EXCESSIVE}

INFLAMMATORY RESPONSE

The initiation of an excessive inflammatory reaction appears to depend on upregulation of T helper $1\left(\mathrm{Th}_{1}\right)$ cells, modulated by the cytokine IL-8. The key to restoration of a more appropriate balance between $\mathrm{Th}_{1}$ and $\mathrm{Th}_{2}$ activity is downregulation of the $\mathrm{Th}_{1}$ cells, modulated by IL-10 and transforming growth factor (TGF) $-\beta .^{53}$ Unfortunately, the model provided by various types of vigorous exercise is of limited value, because these cytokines and the corresponding mRNAs only "overflow" into the bloodstream in minuscule quantities in response to such a stimulus. In an attempt to overcome these difficulties, the exercise stress has been maximised, and the corresponding mRNAs and intracellular cytokine concentrations have been measured in peripheral blood mononuclear cells.

\section{CYTOKINE SECRETION DURING VERY PROLONGED} EXERCISE

Observations made on competitive cyclists 10-25 minutes and 150 minutes after completion of a six hour $250 \mathrm{~km}$ road race in warm weather ${ }^{54}$ show what can be achieved by maximising both exercise and environmental stress. Mean (SD) heart rates over the cycle race were 158 (17) beats/min, $81 \%$ of peak values for this sample of subjects. Changes in immune function were substantially larger than in the laboratory studies of Brenner et al. ${ }^{51}$ The cyclists showed increases in total leucocyte $(100 \%)$, granulocyte $(84 \%)$, lymphocyte (11$15 \%)$, and monocyte (4-5\%) counts, and decreased CD3-CD16CD56 (11\%) counts for at least 2.5 hours after exercise. Blood samples taken 150 minutes after competition showed that counts of the CD3CD8 bright cytotoxic lymphocytes were depressed by $50 \%$. A significant increase in CD 4 cells expressing the IL-2 
receptor $\alpha$ chain was evident 150 minutes after competition, suggesting that there had been either activation of these cells or preferential clearance of naive cells from the circulation. Concentrations of some cytokines were more readily measured than in the laboratory studies, showing patterns and magnitudes of change approximating those of a proinflammatory response. IL-6 concentrations were greatly increased after competition, at both 10-25 minutes (45-fold) and 150 minutes (25-fold). Resting TNF- $\alpha$ concentrations were approximately doubled at both time points after competition, as would be expected from the increases in IL-6. However, plasma levels of IFN- $\gamma$, IL-10, and IL-12 remained below the detection threshold. It thus seems that the responses to exercise come closer to those of a septic reaction if near maximal exercise is maintained for as much as six hours, and stress is augmented by warm environmental conditions.

MRNAS AND INTRACELLULAR CYTOKINES

Because of continuing difficulty in detecting many of the proinflammatory and antiinflammatory cytokines in plasma during and after exercise, the concentrations of mRNAs have been evaluated in peripheral blood mononuclear cells. ${ }^{55}$ Some observations have also been made on intracellular cytokine concentrations ${ }^{5657}$ During septic reactions, mRNAs for cytokines such as IL-6 are found in the liver and intestines. ${ }^{58}$ Flow cytometry suggests that, after eight days of rigorous exercise and cold stress, an increased percentage of macrophages express proinflammatory cytokines intracellularly. ${ }^{57}$ However, after the more moderate stimulus of three hours of exercise at $60 \%$ of aerobic power, the circulating leucocytes show no changes in mRNA concentrations or intracellular concentrations of IL- $6,{ }^{55}$ despite demonstrable increases in plasma concentrations of IL-6. This suggests that, during exercise, there is a second source of these cytokines (for example, the myocytes or macrophages within the muscles), or previously secreted cytokines are released from some storage site as yet to be defined. Ostrowski and associates ${ }^{59}$ were able to detect the mRNA for IL-6 in muscle biopsy specimens from five of eight subjects after they had completed a marathon run; they thus hypothesised that exercise induced microtrauma triggered local intramuscular production of IL-6.

RESPONSES TO MODERATE TRAINING

Twelve weeks of moderate aerobic training augmented resting CD16CD56 NK cell numbers, and blunted fluctuations in lymphocyte subsets (CD4, CD8, and CD19), activation markers (CD25 and CD122), lymphocyte proliferation, and IL-2 release in response to an acute exercise bout of fixed relative intensity. ${ }^{29}$ These various changes suggest that moderate endurance training modulates host defences, reducing the extent of exercise induced inflammatory responses. As may be expected, larger decreases in response are seen if comparisons are made between trained and untrained subjects at the same absolute intensity of effort. $^{60}$

EFFECT OF ANTI-INFLAMMATORY AGENTS AND ENDORPHIN ANTAGONISTS

Some authors have suggested that $\beta$-endorphin is responsible for the exercise induced changes in circulating NK cell count and activity. However, if the underlying cause of the immune disturbance is a typical inflammatory response, there is likely to be a release of prostaglandin, which could be countered by the administration of non-steroidal anti-inflammatory agents.

A double blind randomised block trial used oral naloxone to counter $\beta$-endorphin, ${ }^{61}$ and indomethacin to counter prostaglandin release. ${ }^{62}$ The $\beta$-endorphin antagonist had no effect other than to reduce the exercise induced increment of $\beta$-endorphin, but prostaglandin levels did increase during vigorous aerobic activity. Furthermore, the prostaglandin antagonist was able to reverse the suppression of NK cell activity after exercise, in keeping with the hypothesis of a modest inflammatory reaction. In placebo experiments, the total NK cell activity was suppressed by $28 \%$ two hours after exercise, and lytic activity (as assessed by lysis of K-562 tumour cells) correlated negatively with the increase in $\mathrm{PGE}_{2}$ after exercise (which averaged $36 \%$ ). After indomethacin treatment, the increase in $\mathrm{PGE}_{2}$ after exercise was eliminated, and the suppression of NK cell activity was completely reversed. Thus, the reduction in NK cell activity after exercise seems to be due to the changes in circulating $\mathrm{PGE}_{2}$ that accompany an inflammatory reaction, rather than to an increase in the proportion of lymphocytes with a limited lytic activity consequent on a differential cell redistribution.

\section{Impact of trafficking between circulating and non-circulating leucocytes}

One difficulty in interpreting responses to both exercise and sepsis is that the leucocytes observed in the peripheral blood account for only $1-2 \%$ of the total number in the body. It is thus important to check how far any observed changes in cell characteristics such as cytolytic activity are due to activation by an inflammatory process per se, and how far they reflect an effect of either an alteration in the expression of adhesion molecules or vascular shear forces on the trafficking of leucocytes between the circulation and tissue depots. ${ }^{63}$

Severe trauma is sometimes associated with increased expression of adhesion molecules such as CD11b and CD62L on circulating leucocytes and (after a time delay of a few hours) with parallel changes in soluble L-selectin, ${ }^{64}$ but it is less clear whether these changes are indicative of the risk of sepsis. A study of vigorous exercise showed selective mobilisation of CD4 cells with the CD45RO memory phenotype. The cells that were mobilised carried high levels of the adhesion marker CD11a, and mobilisation of cells seems to be proportional to initial densities of this molecule, suggesting that a change in the expression of adhesion molecules plays an important role in the 
immediate responses of lymphocytes to exercise (GA Gannon, SG Rhind, PN Shek, RJ Shephard, unpublished). The traditional view has been that during exercise the expression of leucocyte adhesion molecules is modified by an action of catecholamines on $\beta_{2}$ adrenergic receptors. ${ }^{65}$ Catecholamines are thought to reduce adhesion forces, causing leucocytes sequestered in the peripheral venules to be released at least temporarily into the circulation. However, it is hard to explain in such terms the strong correlations between counts for some lymphocyte subsets and noradrenaline (norepinephrine) concentrations, because the $\beta_{2}$ receptors respond primarily to adrenaline (epinephrine) rather than noradrenaline. Possibly, noradrenaline acts at sympathetic nerve endings in the lymph glands and/or spleen, ${ }^{66-68}$ or mediates an increase in cardiac contractility and thus in shear forces in the vessels where the leucocytes are sequestrated.

Injection of a physiological $(1 \mathrm{mg})$ dose of adrenaline in sheep induced a significant acute increase in lymph flow, followed by a decrease after injection in both lymph flow and cellular output, ${ }^{69}$ without any change in the relative proportions of lymphocyte subsets or pools of lymphocytes in either blood or lymph. It thus seems unlikely that lymphatic tissue contributes to the leucocytosis after adrenaline injection, although it may contribute to the lymphopenia after exposure to a stressor. The situation during exercise is less clear, because lymph flow is then augmented further by the action of the skeletal muscle pump. However, further research is needed to determine the importance of changes in the expression of adhesion molecules to the overall response, as seen in either sepsis or stressful exercise.

\section{Immune changes during rigorous training}

A modest decline in immune function has been shown in international athletes during peak periods of training, ${ }^{70} 71$ and in some (but not all) instances there has apparently been an associated increase in susceptibility to infection. ${ }^{15}$ However, it is less certain that the type of training undertaken by the average person will show such effects. We conducted field tests of the impact of what was regarded as a rigorous basic infantry training course on the immune function of Canadian Forces recruits. Observations over an 18.5 week programme included the incidence of infections, leucocyte subset counts, cell proliferation, salivary immunoglobulin levels, and the overall intensity of immune responses as assessed by skin reactions to seven common antigens. ${ }^{72}$ Despite a combination of rigorous exercise and some psychological pressures associated with the environment of the new recruits, the incidence of infection remained stable over the course. However, phytohaemagglutinin stimulated lymphocyte proliferation and NK cell activity were significantly increased. Levels of secretory IgA seen in specimens of saliva were somewhat lower by the end of the course, but this may not have been a consequence of the training per se, because many of the recruits were also persuaded to stop cigarette smoking. In vivo cell mediated immunity was assessed by a delayed type hypersensitivity test (the Cell Mediated Immunity (CMI) multitest; Connaught Laboratories, North York, ON, Canada), which evaluates cutaneous reactions to two toxoids (tetanus and diphtheria), three bacterial antigens (streptococcus, tuberculin, and proteus) and two fungal antigens (candida and trichophyton), and a negative control (glycerine). The number of positive reactions and their duration remained unchanged throughout the course. We concluded that the basic infantry training programme had very little overall effect on health or immune responses. ${ }^{72}$ For an inflammatory response to be modelled, subjects would need to undergo either even more intensive training or exposure to prolonged and strenuous endurance exercise in combination with other major stressors-for example, environmental, ${ }^{73}$ psychological, ${ }^{74}$ or nutritional. ${ }^{75}$

\section{Subjects for future research}

Future research on the development of an exercise model of inflammation should not only optimise the physical activity stimulus in subjects who are willing to exercise extremely hard, but should also seek to induce more pronounced immune changes by combining exercise with exposure to other stressors. It would also be interesting to test additional proinflammatory and anti-inflammatory cytokine responses, and to examine the protective effects of various antioxidants and nutritional supplements.

(a) Combinations of stressors. Given the constraint that measurements of human cellular and cytokine responses to stress cannot be examined at the site of tissue injury, the concentrations of many components of the immune response lie below the detection threshold of currently available biochemical and immunological kits, whether measurements are made in the plasma, intracellularly, or as mRNA. ${ }^{56}$ The response of key cellular elements, proinflammatory and antiinflammatory cytokines, should thus be studied under the worst conceivable conditions tolerated by an athlete; exercise should be combined with other stressors such as psychological pressures, high environmental temperatures, and a negative energy balance.

(b) Additional cytokine research. Assuming that the combined stressors are more effective in inducing the alterations of immune response expected during inflammation, detailed study should be made of changes in the balance between proinflammatory $\mathrm{Th}_{1}$ products (IL-2, IFN $-\gamma$ ) and anti-inflammatory $\mathrm{Th}_{2}$ products (IL-4, IL-5, IL-6, IL-10), as well as IL-8, TNF- $\alpha$, TGF- $\beta$, and leukotriene B4 levels. These data should also be related to information on levels of $\mathrm{PGE}_{2}$, cortisol, and other hormones.

(c) Protective measures. If such an approach yields an adequate model of the inflammatory response, it will then be appropriate to explore the efficacy of various prophylactic and/or therapeutic agents such as free radical antagonists, nutritional supplements, and anti-inflammatory 
agents in terms of their ability to reverse cellular and humoral changes and modulate the response to cutaneously administered antigens.

1 Bone RC, Balk RA, Cerra FB, et al. Definitions for sepsis and organ failure and guidelines for the use of innovative therapies in sepsis. Chest 1992;101:1644-55.

2 Marshall JC. The gut as a potential trigger of exerciseinduced inflammatory response. Can $\mathcal{F}$ Physiol Pharmacol 1998;76:479-84.

3 Alexander JW, Boyce ST, Babcok GF, et al. The process of microbial translocation. Ann Surg 1990;212:496-510.

4 Bosenberg AT, Brock-Utne JG, Gaffin SL, et al. Strenuous exercise causes systemic endotoxemia. F Appl Physiol 1988; 65:106-8.

5 Jones WG, Minci JP, Barber AE, et al. Bacterial translocation and intestinal atrophy after thermal injury and burn wound sepsis. Ann Surg 1990;211:399-405.

6 Moore GE, Holbein ME, Knochel JP. Exercise-associated collapse is unrelated to endotoxemia. Med Sci Sports Exerc 1995;27:1238-42.

7 Santos AA, Wilmore DW. The systemic inflammatory response: perspectives of human endotoxaemia. Shock response: perspectives

8 Shephard RJ, Shek PN. Immune responses to inflammation and trauma: a physical training model. Can 7 Physiol Phar and trauma: a physical

9 Shephard RJ, Shek PN. Physical activity and immune changes: a potential model of subclinical inflammation and sepsis. Crit Rev Phys Med Rehabil 1996;8:153-81.

10 Shek PN, Shephard RJ. Physical exercise as a human mode of subclinical inflammatory response. Can 7 Physio Pharmacol 1998;76:589-97.

11 Camus G, Deby-Dupont G, Duchateau J, et al. Are simila inflammatory factors involved in strenuous exercise and sepsis? Intensive Care Med 1994;24:602-10.

12 Northoff H, Enkel S, Weinstock C. Exercise, injury and immune function. Exerc Immunol Rev 1995;1:1-25.

13 Northoff H, Berg A, Weinstock C. Similarities and differences of the immune response to exercise and trauma: the IFN- $\gamma$ concept. Can F Physiol Pharmacol 1998;76:497504

14 Nieman DC. Exercise and resistance to infection. Can $\mathcal{F}$ Physiol Pharmacol 1998;76:573-80.

15 Shephard RJ. Overview of the epidemiology of exercise immunology. Immunol Cell Biol 2000;78:485-95.

16 Hoffman-Goetz L, Kubes P, Shephard RJ. Immune responses to inflammation and trauma: a physical training model. Can f Physiol Pharmacol 1998;76:469-597.

17 Fielding RA, Manfredi TJ, Ding W, et al. Acute phase response in exercise. III. Neutrophil and IL-1 beta R166-72.

18 Jones DA, Newham DJ, Round JM, et al. Experimental human muscle damage: morphological changes in relation to other indices of damage. F Physiol (Lond) 1986;375:43548.

19 Round JM, Jones DA, Cambridge G. Cellular infiltrates in human skeletal muscle: exercise-induced damage as a model for inflammatory muscle disease? F Neurol Sci 1987; 82:1-11

20 Dufaux B, Order U. Complement activation after prolonged exercise. Clin Chim Acta 1989;179:45-9.

21 Hansen JB, Wilsgard L, Osterud, B. Biphasic changes in leukocytes induced by strenuous exercise. Eur $\mathcal{F} A p p l$ Physiol 1991;62:157-61.

22 Smith JA, Pyne DB. Exercise, training, and neutrophil function. Exerc Immunol Rev 1997;3:96-117.

23 Camus G, Duchateau J, Deby-Dupont G, et al. Anaphylotoxin $\mathrm{C} 5 \mathrm{a}$ production during short-term submaximal dynamic exercise in men. Int $\mathcal{F}$ Sports Med 1994;15:32-5.

24 Smith EM. Hormonal activities of cytokines. Chem Immuno 1991;52:154-64.

25 Gannon GA, Rhind S, Shek PN, et al. Circulating levels of peripheral blood leukocytes and cytokines following competitive cycling. Can ₹ Appl Physiol 1997;22:133-47.

26 Pedersen BK, Ostrowski K, Rohde T, et al. The cytokine response to strenuous exercise. Can $\mathcal{F}$ Physiol Pharmacol 1998;76:505-11.

27 Cannon JG, Meydani SN, Fielding RA, et al. Acute phase response to exercise. II. Associations between vitamin E,
cytokines, and muscle proteolysis. Am F Physiol 1991;260: R1235-40.

28 Northoff H, Weinstock C, Berg A. The cytokine response to strenuous exercise. Int f Sports Med 1994;15:S167-71.

29 Rhind SG, Shek PN, Shinkai S, et al. Effects of moderate endurance exercise and training on in vitro lymphocyte proliferation, IL-2 production and IL-2 receptor expression. Eur F Appl Physiol 1996;74:348-60.

30 Shek PN, Sabiston BH, Buguet A, et al. Strenuous exercise and immunological changes: a multiple-time-point analysis of leukocyte subsets, CD4/CD8 ratio, immunoglobulin production and NK cell response. Int 7 Sports Med 1995;16:466-74.

31 Brenner IKM, Severs YD, Shek PN, et al. Impact of heat exposure and moderate, intermittent exercise on cytolytic exposure and moderate, intermittent ex

32 Severs Y, Brenner IKM, Shek PN, et al. Effects of heat and intermittent exercise on leukocyte and subpopulation cell counts. Eur f Appl Physiol 1996;74:234-45.
33 Verde TJ, Thomas S, Moore RW, et al. Immune responses and increased training of the elite athlete. $\mathcal{F}$ Appl Physiol 1992;73:1494-9.

34 Mackinnon LT. Exercise and immunoglobulins. Exerc Immunol Rev 1996;2:1-34.

35 Castell LM, Poortmans JR, Leclerq R, et al. Some aspects of the acute phase response after a marathon race, and the effects of glutamine supplementation. Eur f Appl Physiol 1997;75:47-53.

36 Brenner IKM, Shek PN, Shephard RJ. Infection in athletes. Sports Med 1994;17:86-107.

37 Shephard RJ, Shek PN. Infectious diseases in athletes: new interest for an old problem. F Sports Med Phys Fitness 1994; 34:11-22

38 Shephard RJ, Shek PN. Exercise, immunity, and susceptibility to infection. Physician and Sportsmedicine 1999;27:4771

39 Shephard RJ, Shek PN. Cancer, immune function, and physical activity. Can f Appl Physiol 1995;20:1-25.

40 Shephard RJ, Futcher R. Physical activity and cancer: how may protection be maximized? Crit Rev Oncog 1997;8:21972 .

41 Shephard RJ, Shek PN. Does regular physical activity reduce susceptibility to cancer? In: Shephard RJ, ed. Auckland: Adis International, 2000;131-54.

42 Nieman DC, Johanssen LM, Lee JW. Infectious episodes in runners before and after a roadrace. $\mathcal{F}$ Sports Med Phys Fitness 1989;29:289-96.

43 Nieman DC, Berk LS, Simpson-Westerberg M, et al. Effect of long endurance running on immune system parameters and lymphocyte function in experienced marathoners. Int $\mathcal{F}$ Sports Med 1989;10:317-23.

44 Shephard RJ. Physical activity, training and the immune response. Carmel, IN: Cooper Publications, 1997.

45 Shephard RJ, Shek PN. Effects of exercise and training on natural killer cell counts and cytolytic activity: a metaanalysis. Sports Med 1999;28:177-95.

46 Nielsen HB, Secher NH, Pedersen BK. Lymphocytes and NK cell activity during repeated bouts of maximal exercise. [abstract] Int f Sports Med 1997;18:S112.

47 Suzui M, Nagao F, Takeda K, et al. Is ventilatory threshold a key to open the window of natural killer cell cytotoxicity? [abstract] Med Sci Sports Exerc 1998;30:S19.

48 Suzui M, Nagao F, Takeda K, et al. Do temporary anaerobic efforts open the window of natural killer cell cytotoxicity? [abstract] Med Sci Sports Exerc 1999;31:S61.

49 Kappel M, Tvede N, Galbo H, et al. Evidence that the effect of physical exercise on NK cell activity is mediated by epinephrine. F Appl Physiol 1991;70:2530-4.

50 Shore S, Shinkai S, Rhind S, et al. Immune responses to training: how critical is training volume? F Sports Med Phys Fitness 1999;39:1-11.

51 Brenner IKM, Natale VM, Suntres ZE, et al. Impact of different types of exercise on components of the inflammatory response. Eur f Appl Physiol 1999;80:452-60.

52 Ottaway CA, Fong IW, da Silva B, et al. Integrative aspects of a human model of endotoxemia. Can F Physiol Pharmacol 1998;76:473-8.

53 Mosmann TR, Coffman RL. Heterogeneity of cytokine secretion patterns and functions of helper T cells. $A d v$ Immunol 1989;46:111-47.

54 Gannon GA, Rhind SG, Suzui M, et al. Changes in selected cellular and soluble mediators of immunity following a $250-\mathrm{km}$ competitive road-cycling race. Int 7 Sports Med 1997;18:S108.

55 Moldoveanu A, Shephard RJ, Shek PN. Prolonged exercise elevates plasma levels but not gene expression of IL-1 $\beta$,
IL-6, and TNF $\alpha$ in circulating mononuclear cells. $\mathcal{F}$ Appl Physiol 2000;89:1499-504.

56 Moldoveanu A, Shephard RJ, Shek PN. The cytokine response to physical activity and training. Sports Med 2001; 31:115-44

57 Rhind SG, Castellani JW, Brenner IKM, et al. Intracellular and serum cytokine profiles following exhausting exercise and cold exposure. Am F Physiol 2001;281:R66-75.

58 Nelson JL, Wesley AJ, Mao J-X, et al. Effect of pentoxifylline on survival and intestinal cytokine messenger RNA transcription in a rat model of ongoing peritoneal sepsis. Crit Care Med 1999;27:113-19.

59 Ostrowski $\mathrm{K}$, Rohde $\mathrm{T}$, Zacho $\mathrm{M}$, et al. Evidence that interleukin- 6 is produced in human skeletal muscle during prolonged running. F Physiol 1998;508:949-53.

60 Evans WJ, Meredith CN, Cannon JG, et al. Metabolic changes following eccentric exercise in trained and changes following eccentric exercise in tran
untrained men. F Appl Physiol 1986;61:1864-8.

61 Gannon GA, Rhind SG, Suzui M, et al. $\beta$-Endorphin and natural killer cell cytolytic activity during prolonged exercise. Is there a connection? Am f Physiol 1998;275: R1725-34.

62 Rhind SG, Gannon GA, Suzui M, et al. Indomethacin inhibits circulating PGE2 and reverses postexercise suppression of natural killer cell activity. $A m$ f Physio 1999;276:R1496-505.

63 Shephard RJ, Gannon G, Hay JB, et al. Adhesion molecule expression in acute and chronic exercise. Crit Rev Immunol 2000;20:245-66.

64 Maekawa K, Futami S, Nishida M, et al. Effects of trauma and sepsis on soluble L-selectin and cell surface expression of L-selectin and CD11b. F Trauma 1998;44:460-8.

65 Murray DR, Irwin M, Rearden CA, et al. Sympathetic and immune interactions during dynamic exercise. Mediation via a beta-2-adrenergic-dependent mechanism. Circulation 1992;86:203-13. 
66 Bellinger DL, Ackerman KD, Felten SY, et al. Noradrenergic sympathetic innervation of thymus, spleen and lymph nodes: aspects of development, aging and plasticity in neural immune interaction. In: Hadden JW, Masek K, Nistico G. eds. Interactions among CNS, Neuroendocrine and immune systems. Rome: Pythagora Press, 1989:35-66.

67 Bullock K, Radojcic T. Characterization of muscarinic acetyl choline and beta-adrenergic receptors on fresh and cloned immunocytes. In: Hadden JW, Masek K, Nistico G, eds. Interactions among CNS, neuroendocrine and immune systems. Rome: Pythagora Press, 1989:17-34.

68 Iversen PO, Arvesen BL, Benestad HB. No mandatory role for the spleen in the exercise-induced leucocytosis in man. Clin Sci 1994;89:505-10.

69 Seabrook TJ, Ristevski B, Rhind SG, et al. Epinephrine causes a reduction in lymph node cell output in sheep. Can $\mathcal{F}$ Physiol Pharmacol 2001 ; in press.
70 Mackinnon LT, Chick TW, van As A, et al. Decreased secretory immunoglobulins following intense endurance exercise. Sports Training and Medical Rehabilitation 1989;1:209-18.

71 Nieman DC. Exercise, upper respiratory tract infection, and the immune system. Med Sci Sports Exerc 1994;26:128-39.

72 Brenner IKM, Severs YD, Rhind SG, et al. Immune function and incidence of infection during infantry training. Mil Med 2000;165:878-83.

73 Shephard RJ. Immune changes induced by exercise in an adverse environment. Can $\mathcal{F}$ Physiol Pharmacol 1998;76: 539-46.

74 Schedlowski M, Jacobs R, Stratmann G, et al. Changes of natural killer cells during acute psychological stress. $\mathcal{F}$ Clin Immunol 1993;13:119-26.

75 Nieman DC, Pedersen BK. Nutrition and exercise immunology. Boca Raton, FL: CRC Publishers, 2000.

\section{Take home message}

- Exercise has been suggested as a model for the study of sepsis and the inflammatory response.

- Although there are qualitative similarities in immune responses between the two types of stimulus, the reactions to most forms of exercise are on a much smaller scale than in sepsis, and in consequence they are more difficult to measure accurately.

- If exercise is to be used as a model in developing antidotes to an excessive inflammatory response, it will be necessary to use bouts of heavy and prolonged physical activity, augmenting this stimulus with other stressors such as thermal extremes or nutritional deficiencies.

\section{Commentary}

Although there are a large number of studies detailing immune and inflammatory responses to exercise, it is timely to examine this body of work in the light of broader applications to clinical medicine. Using exercise as an experimental model for examination of discrete aspects of sepsis and inflammation will, as Professor Shephard notes, facilitate a better understanding of the qualitative similarities and the quantitative differences between the two. Whether experimentally manipulated exercise can satisfactorily reproduce the magnitude of the inflammatory response observed in critical care medicine remains a problem. It is clear that selection of subjects and the choice of experimental treatment are the critical factors. Shephard is correct in promoting a multifaceted approach in which novel, prolonged, exhaustive, and possibly eccentrically biased exercise loads are coupled with other environmental, psychological, and nutritional stressors to invoke a sufficient inflammatory response.

DAVID PYNE 